\title{
BARMHARTIGHEID, BARMHARTIGHEIDSDIENS, DIE DIAKONAAT EN DIE PRAKTYK
}

\author{
Dr. K. S. van W. de Vries
}

\section{Prakties wees}

Ons moet realisties Christen wees en realisties kerk wees. Om op 'n laaste en uitsluitende woord te wag oor die amp van die diaken/diakones en die diens van die barmhartigheid voordat ons uit die status quo, uit die gestagneerde en dodelik gestruktureerde van ons diakonaat uitbreek tot die lewe van waaragtige barmhartigheid, is ydel en fariseisties en wettisisties.

Ons moet ook prakties, daadwerklik Christen wees en kerk wees in ons aardse tranedal. Inderdaad, ons moet dink en studeer en na die Bybel luister maar ons moet ook lewend doen en beweeg as ons na die Bybel luister; dink èn doen is dit tog (Fil. $4: 8,9$ ) maar by ons het die doen vasgeval in die eindelose gedink. Die een kan mos nie sonder die ander nie. Die gedagte is tog die vrugbare moeder van die daad en nie 'n steriele vrou of een wat telkens tot by die geboorte laat kom maar nie die krag het om te baar nie (Jes. $37: 3$ ).

\section{Kerk in stagnasie?}

Dit is so dat die ware kerk vandag in 'n stroomversnelling van destrukturering (selfs de-struksie) en de-institusionalisering klein word en voel asof God se diep waters oor hom heen gaan (Ps. 42 : 8 en Jona $2: 5$ ) terwyl dit al die tyd die modderige slyk (Ps. $40: 3$ ) van die dodelike leuenagtige horisontaliste en humaniste is wat sê dat hulle hulle naaste (lees: medemens!) lief het maar God haat (1 Joh. $4: 20$ by implikasie) en wat net die ene daad wil wees en die geloof en die beginsel dood maak (Jak. 2 by implikasie). Aan die ander kant is dit ook so dat die ware kerk klein word in die versmorende strukturering en institusionalisering, miskien uit reaksie teen en vrees vir die teendeel, wat niks anders is as fariseïsme en wettisisme en selfs konfessionalisme nie. Aan beide kante word die Bybel toegeklap en die Here Jesus Christus stil gemaak.

Ons moet uit hierdie klem en stagnasie uit breek. Laat die geleerdes dan leer en dit goed doen en laat ons na hulle luister. Intussen probeer ek doen en dink ek dat ons moet doen, want ons het al baie geleer deur die Heilige Gees wat die Skrifte in ons hart laat lig omdat dit tot ons lering geskrywe is (Rom. $15: 4$ ). En die lering hou benewens die Christelike hoop deur aanhou en uithou die geloof in $(15: 4,5,13)$, seer sekerlik ook in die barm. hartigheid van God en van sy volk en aan sy volk en aan alle nasies $(15: 8,9)$. 


\section{Wat is Barmhartigheid?}

Wat is die barmhartigheid waaroor alles eintlik gaan? Die antwoord op die vraag is alleen sinvol as ons begin by die barmhartigheid van God want ons het immers die opdrag van Jesus Christus ontvang om barmhartig te wees soos ons Vader ook barmhartig is (Luk. $6: 36)$. God se barmhartigheid, ontferming, erbarming, goedertierenheid is sy goedheid en liefde wat Hy daadwerklik betoon aan ellendiges, behoeftiges, treurendes, benoudes, skuldiges, teneergedruktes, vervolgdes, gehates en godvresendes wat smag na die waarheid van God ( $u$ vind al hierdie ,toestande" in Ps. 86), bejaardes (Ps. 71), eensames (Ps. 27), bekommerdes en die wat sug en struikel (Ps. 31), gebrokenes van hart en verslaenes van gees (Ps. 34), teëspoediges (Ps. 34), swakkeres (Ps. 35: 10), verontregtes en ongelukkiges (Ps. 35), regverdiges (Ps. 37), siekes (Ps. 38) - dis nog maar slegs 'n paar Psalms en die hele Bybel lê voor. Ons kan tog nie die lang lys voltooi nie want dit is so lank en groot soos God se barmhartigheid (Ps. 86, Ps. 119 : 156), so eindeloos en hoog (Ps. 103), veelvuldig en roemryk. Hy bewys dit aan duisende en van geslag tot geslag vir wie Hom vrees; dit gaan die liefde van 'n vader of moeder ver te bowe en is ten volle geopenbaar iin sy Seun, die barmhartige Hoëpriester wat medelyde met ons het (Hebr.) oor ons swakhede en wat deur die wederbarende en vernuwende werking van sy Heilige Gees ons leer om barmhartig te wees soos ons Vader barmhartig is.

God se barmhartigheid is sy hart en hand en Woord wat uitgaan om te troos, as ons begryp wat troos werklik is, en wat volmaak, dit is konsekwent, is oor alle mense (Matt. $5: 48$ ) en óns leer om volmaak te wees (in ons barmhartigheid) soos ons Vader in die hemel volmaak is. Want Hy laat die son opgaan oor slegtes en goeies en $\mathrm{Hy}$ laat reën op regverdiges en onregverdiges (Matt. $5: 45)$. Hy skyn in die harte van mense deur die wet daarin te skrywe (Rom. 2 : 14, 15) en is ryk en lankmoedig in sy barmhartigheid oor die mense (Rom. 2 : 4) en die HERE is vir almal goed en sy barmhartigheid is oor al sy werke (Ps. 145). En deur God se groot barmhartigheid heen skitter die lig van sy verbond waarvan Hy die beloftes waar maak aan duisende en duisende mense (Ex. 20; $34: 6,7 ; 2$ Kron. $30: 9$ ) in al hulle geslagte in Christus Jesus ons Hoëpriester.

\section{Barmhartigheid 'n opdrag}

Nou moet óns dit óok wees, sê Christus, konsekwent barmhartig wees, ook aan ander en selfs aan die wat aan ons nie goed doen nie, ons vyande. Dán sal ons kinders van die Allerhoogste wees (Luk. $6: 35$ ). Paulus sê dit anders: doen goed aan alle mense, veral aan die medegelowiges en moet nie moeg word om dit te doen nie (Gal. $6: 9,10$; Rom. $12: 17$ ). Dit is die tekenende beeldskap van die gelowige dat hy barmhartig is (vgl. die onbarmhartige skuldeiser en die barmhartige Samaritaan, Matt. 18). Salig is die barmhartiges inderdaad (Matt. 5 : 7). Die gelowige, die egte sagmoedige (Matt. $5: 6$ ) en die ware kind van die Allerhoogste (Luk. 
$6: 35)$ reageer barmhartig op allerlei menslike nood en verhard sy hart nie daarteen nie. Want as Christus die eindoordeel beskrywe, is juis die barmhartigheid wat aan mense bewys is die toetssteen vir die ingang in die koninkryk van God (Matt. 25).

Deur die geloof wat die Heilige Gees in ons tot stand bring, is ons sensitief vir menslike nood - stoflik, sielkundig, maatskaplik, geestelik - en ook gebonde om te help, te help dra aan laste, te gee (H.K. 21) sonder om na die koste te vra maar om te kyk na die oorvloed wat God ons bewys (2 Kor. 8 : 2 vv). Maar ook om realisties barmhartig te wees wel wetende dat dit soms misplaas is en soms verkeerd geïnterpreteer word, soms afgewys word en bespot deur die sekulêre gemeenskap, terwyl ons die hoë doel alleen uiteindelik bereik in die krag van Jesus wat ons gegryp het uit die kloue van die onbarmhartige dood.

\section{Diakonia-in-Christus}

En om oplettend realisties te wees sodat ons weet dat die homogenisasie van woon- en belangebuurt van die moderne maatskappy dikwels die afskorting is wat die mensenood voor ons oë verberg dog die feit daarvan nie uit die gedagte wegneem nie. Die Heilige Gees laat ons juis daarom steeds terugkeer na die enigste Bron van alle volmaakte barmhartigheid, God die Here in Jesus Christus wat Here en Meester is maar Homself verneder het tot dienskneg (Rom. 15:8) en slaaf (Fil. $2: 6$ ). Hy, die Diakonos, gaan ons voor in die diakonia wat vir ons ten diepste beteken deelgenootskap deur genade aan die diens van Christus Jesus. Hierdie diakonia-in-Christus kenmerk die gelowige en die gemeenskap van die gelowiges, die kerk. Ons is deelhebbers, medearbeiders, in die gemeenskap en in die liggaamlike diensbaarheid en in die lyde van die Kneg van die Here (Fil. 2 : 5-11; Kol. 1 : 24-28). Hierdie diakonia is ' $n$ onderskeidende gawe van die Heilige Gees binne in en aan die liggaam van Christus en openbaar hom in allerlei barmhartigheidsbetoning (Rom. 12: 7; 1 Petr. 4 : 7 vv).

So is God die Vader die Bron van alle barmhartigheid en Jesus Christus die volmaakte openbaring daarvan en die kinders van die hemelse Vader die dienaars of bedienaars daarvan om deur die bediening die beeld van die Here Jesus Christus te toon wat die afskynsel van die Vader is!

\section{Christus laat diensbetoon bo institusionalisering gaan}

Jesus Christus beveel die gelowiges hierdie diensbetoon en spoor hulle daartoe aan maar Hy institusionaliseer en konstruktureer dit nie. Hy roep manne om dit besonderlik te reël en te rig en te organiseer (Hand. 6) maar nie om dit te stagneer en te reglementeer nie. Hy wek hulle op om dit onder die aandag te bring (2 Kor. 8) van en bekend te maak aan sy liggaam. Hy laat ons weet en voel dat die liggaam ly as een lid ly (1 Kor. $12: 28)$ en dat ons in die gemeenskap moet volhard om die lydende lid in die liggaam te hou en te help. Hy leer en beveel ons om ons naaste lief te hê soos onsself en dat ons naaste van ons die persoonlike, 
bewuste, innerlike barmhartigheid benodig en dat dit enige iemand is wat met sy nood op ons weg of in ons blikveld kom. Hy leer ons dat sy liggaam, die gemeenskap van die heiliges, gemeenskap moet bly omdat alle lede mekaar nodig het en alle lede saam die een liggaam vorm ( 1 Kor. 12 ; Rom. 12) en die een lid of alle lede die lydende lid barmhartigheid moet bewys ter bewaring van die gehele liggaam. En Hy leer ons dat die lydende of treurende of belaste na Hom toe moet kom, moet vra en vra en van Hom verlossing uit benoudheid sal ontvang en van die kinders van die Vader leniging in hulle nood sal erlang.

So leer die Skrif my dat God in Christus Jesus barmhartig is, dat ons gelowiges barmhartig is, dit moet wees en dit daadwerklik moet toon en betoon, dat die betoning daarvan ' $n$ diens is, kenmerkend van die lid en lede en hele liggaam van Christus, die DIAKONOS van God, dat Christus in sy liggaam en vir sy liggaam en vir alle mense manne roep om besonderlik in hierdie diens van die barmhartigheid die bediening te behartig, te koördineer en te reël, te rig en te organiseer. Hierdie bediening is ingestel in die kerk, die gemeenskap, en is noodsaaklik vir die welwese daarvan. Maar omdat ons weet dat God barmhartig is oor alle mense en oor al sy werke, erken ons die ontstaan van differensiasie in barmhartigheidsbetoon in die geskiedenis en beskou dit nie as uitsluitlik 'n kerklike diens nie. Die kerklike instituut met sy noodsaaklike barmhartigheidsdiens is nie hoër in orde of belangriker as dié van die gesin of die owerheid of die welsynsorganisasie nie. Dit is wel anders maar in almal lewe op een of ander wyse die koninkryk van God (Kol. 1 : 13-20). Die diakonaat is nie primêr en hoef dit nie te wees vir die owerheid se welsynsorg nie en is nie orals en altyd die aangewese instansie vir hulp en sorg nie (Rom. 13; 1 Tim. $2: 2,5: 16$ ).

Primêr is en bly dat as iemand in nood is hy gehelp moet word. Die iemand kan enige-iemand wees want Gal. 6 : 10 gee orde en nie rangorde nie.

En primêr bly dat die diaken, die diakonaat van die instituut van die kerk, die barmhartigheid van Jesus Christus sigbaar moet maak as ' $n$ diensbetoning waarin en waaragter die barmhartigheid van al die kinders van God moet blyk in volledige konsekwentheid. Maar as 'n lid van die liggaam van Jesus, as 'n lidmaat van die kerk ondersteuning of hulp van die owerheid of 'n welsynsorganisasie ontvang plaas dit hom tog nie buite die koninkryk van God of die kerklike barmhartigheidsdiens nie want hy maak van sy burgerreg gebruik en die owerheid is ook ' $n$ instelling van God. Ons kan die diakonaat nie absoluut skei van die owerheidstaak nie; daar is oorvleueling.

\section{Barmhartigheidsdiens moet verantwoord wees}

En primêr bly dat die manier van barmhartigheidsbetoon verantwoord moet wees. Van die gelowige en van die diakonaat is dit ' $n$ diens wat deur liefde bewoë is en 'n medium waardeur die geloof werksaam is ter wille van die lid, lede, gemeenskap van die 
heiliges én alle mense om meer en meer die beeld van Christus te toon. Dit is die kerk se verantwoording. Die owerheid se verantwoording en manier is 'n departement waardeur hy op wetenskaplike wyse probeer versorg deur 'n uitgebreide en gedifferensiecrde staf van deskundiges. Miskien, nee sekerlik, moet die diakens dit beter doen. Hulle moet in die gemeente gawes en talente soek en ontdek on integreer in die diensbetoon met die mandaat van wat hulle in staat stel om ver beter te doen as ander omdat hulle die lid en lede en diegene wat barmhartigheid ontvang in direkte verhouding met Christus bring deur die werking van die Gees en die Woord.

En primêr bly dat juis hierdie Bybelse blik op die diens hemelsbreed verskil van die blik van die Marxisme en humanisme, van die "human rights" en die gebasel oor „elkeen eweveel of die gemeenskap wat die een en al is" (hierop gaan ek nie verder in nie omdat oor hierdie tema ander met groter bekwaamheid as ek gerefereer en geskrywe het).

En primêr bly dat wanneer hierdie diens vermaterialiseer, versinodaliseer, in onpersoonlikheid, ongeërgdheid en onbetrokkenheid verarm en verskraal en ongeïdentifiseerd in die lug bly swewe, sy blikveld laat inkrimp tot amper niks nie, sy wese verkrag deur gesistematiseerde reglementering en egoïsties en fariseĩsties na binne gekeer raak, die barmhartigheid verwurg word en wegsterwe. Hierdie soort diens of bediening blokkeer die stroom van die barmhartigheid en laat die kerk sterf. Dit vertoon nie meer die beeltenis van die Here Jesus Christus nie maar van iets of iemand anders. Laat ons gewaarsku wees!

\section{Om uit die moddergat te kom}

Al hierdie dinge is oorbekend en dikwels gesê en geskrywe. Maar ek het dit weer gesê sodat ons die moddergat waarin ons vasgeval het kan raaksien vir wat dit is. En laat ons probeer om sinvol, eietyds en tot eer van God die dinge opnuut reël en organiseer en koördineer om uit die moddergat uit te kom. En laat ons dit dan doen van uit die feitelikheid dat daar binne en buite die gemeente baie mense is wat ly en smag na barmhartigheid; en van uit die beginsel dat daar diakens moet wees vir hierdie diens; en van uit die waarheid en werklikheid dat dit nie die diakens is wat húlle barmhartigheid betoon nie, maar dat die diakens die barmhartigheid van die gemeenskap van die heiliges, die gemeente, openbaar en van krag makk om sodoende die barmhartigheid van die Hoof van die gemeente, van wie dit eintlik kom, te toon.

Die diakens lewer hierdie diens plaaslik, in en rondom die plaaslike kerk. Dáár bevind die lydende lede van die liggaam hulle en dáar plaas die Here ook ander noodlydendes op die weg van sy gemeente en elke lid daarvan.

Die lydende mens meld hom aan, vra hulp, roep daarom en word gehoor en raak gesien deur die diaken of ouderling of predikant of gelowige. Daarom moet die gelowige, die diakens en ander, met oop en soekende oë rondbeweeg. 
Dit is die taak van die diakens, gehelp deur die gemeente en in samehang met die diens van die ouderlinge en predikante, om die betrokke nood te identifiseer en na sy omvang, intensiteit en betekenis te evalueer.

Die diakens moet die manier en die aard van die hulp en noodleniging wat betoon moet word, sorgvuldig vasstel sodat dit wesenlik barmhartigheidsbetoon is.

Die diakens moet hierdie nood aan die gemeente bekend stel. Dit moet gespesifiseerd en persoonlik (na die hart) geskied om die barmhartigheid van die gemeente op te roep en te rig sodat daar gemotiveerd en bewustelik geoffer word.

Vir al hierdie diakonale take is spanwerk van die predikante, ouderlinge en diakens nodig. Ons moet ophou om hierdie drie in hulle dienswerk hermeties van mekaar te skei.

Ook nodig is kennis. 'n Soort opleiding is noodsaaklik; hulp en advies van deskundiges moet ingeroep word; die nood is gevarieer, dikwels gekompliseer, dikwels afgeskerm van die onkundige se oë en insig.

Wykindeling van 'n gemeente is vir die ouderlinge en predikante goeie organisasie, maar elke wyk hoef nie 'n diaken te hê nie.

Kerkrade moet weg beweeg van die gedagte dat diakens jonk en onervare moet wees!

Die gemotiveerdheid, kennis, identifikasie, evaluering en beplanning is 'n groot taak. Dit bring noodwendig die vraag na vore na die nodige en/of noodsaaklike verband met en raadpleging van die kerkverband en instansies van hulpverlening soos die owerheid en die welsynsorganisasies. In die feitelike situasie van die Gereformecrde Kerke in Suid-Afrika dink ek hieroor soos volg:

1. Die diakens vorm nie 'n kerklike vergadering nie. Hulle diens en organisasie van die diens is en bly deel van die kerkraadswerk. Omdat daar geen mindere-aparte-kerk-diakonale-vergadering is nie, is daar ook geen meerdere-aparte-kerk-diakonale-vergadering nie. Die diens van die barmhartigheid is taak van die kerkraad en die klassis. Deur middel van hierdie vergaderings kan die diakens van een ressort raadpleeg met en hulp vra van diakens van ander ressorte en die werksaamhede desgewens gekoördineerd organiseer. Vir sover dit die belydenis en die kerkorde betref kan vir prinsipiële studie, stelling en uitsluitsel en vir identifikasie, en evaluering en bekendstelling van nood in die buiteland, die diakonale werksaamhede reëling wees van die nasionale en/of algemene sinodes.

2. Deputate vir diakonale sake van die sinode moet afgeskaf word in die konteks van punt 1 hierbo. Eweneens moet die praktyk van konferensies vir diakens (en wat dit betref vir ouderlinge en predikante ook) gestaak word. Die patroon van die GTV en opfrissingskursusse van die teologiese skole kan miskien vir diakens aangewend word.

3. Die verband met die owerheid is gereël deur wetgewing van 1937, d.w.s. die owerheid laat die taak van sekere welsynsaspekte en -versorging vir 'n groot deel oor aan welsynsorganisasies cn verwelkom die daarstelling van sulke organisasies deur kerke maar sien ook graag dat die kerke t.a.v. welsynsorganisasies wat 
hulle inisieer koördinerend en sentraliserend werk. T.a.v. die Gereformeerde Kerke is die feitelike situasie verwarrend en werk dit verbrokkelend.

Histories het die Deputate vir Diakonale Sake ontwikkel; dit is 'n maatskappy sonder winsbejag en stig welsynsorganisasies vir sy ondernemings. Later het die Gereformeerde Stigting vir die Versorging van Bejaardes en die Jeug op inisiatief van 'n kerkraad (later kerkrade) met wye bevoegdhede ontstaan en wat baie groter as eersgenoemde is. Nog ander welsynsorganisasies is en word deur kerkrade in die lewe geroep. 'n Eienaardige en diskriminerende en tweeslagtige redenering het rondom die Deputate en die welsynsorganisasie(s) ontstaan. Die bewering is al gemaak dat die Deputate meer en suiwerder "des kerks" is vanweë die sinodale beheer en die ander dit minder is vanweë beheer deur kerkrade. Die bewering hou allermins steek. Die gedagte dat die een egte barmhartigheidsdiens is en die ander 'n soort afgewaterde liefdadigheid(!), is uit die lug gegryp. Dat die een met sinodale mandaat in die kerkverband (d.w.s. direk aan die adres van ,alle diakonieë") hulp vra vir die oprigting van en verbeterings aan geboue is goed gereformeerd; die ander weerhou hom konsekwent van dergelike hulpaanvraag (vir oprigting en verbeterings) want as hy dit doen is dit onkerkregtelik en daarom ongereformeerd. Oprigting van geboue mag dus in die een geval wel sinodale werk wees maar is in die ander geval beslis nie kerkwerk nie. Ons moet uit die impasse van hierdie soort redenering kom. Dit is ons nie waardig nie. (Let asb. wel: ek sou baie dankbaar wees indien die geld vir die noodsaaklike verbeterings aan die kindertehuis te Johannesburg in 'n kort tydjie deur ons diakonieë bymekaar gebring kon word!).

4. Dit het tyd geword dat ons die situasie nugter en realisties in oënskou neem en tegelykertyd prinsipieel dink sonder om in die historiese gewordenheid die een teenoor die ander af te speel, want die een én die ander word beide gedruk deur kerkregtelike besware. Daarvoor is m.i. noodsaaklik die volgende:

4.1. Realistiese en sinvolle inpassing by die owerheidsreëling.

4.2. Ons moet duidelik onderskei tussen kerkwerk en werk van die welsynsorganisasie wat deur die kerk geïnisieer is.

4.3. Die Deputate vir Diakonale Sake en die Gereformeerde Stigting en ander welsynsorganisasies moet verenig in een enkele omvattende gereformeerde welsynsorganisasie waarvan die bestuurslede daargestel word deur plaaslike kerke en/of klasses. Diakens/ diakonesse moet vir die behartiging van die barmhartigheidsdiens ten nouste met die welsynsorganisasie saamwerk t.o.v.

4.3.1. identifikasie van behoeftes en voorsiening daarin;

4.3.2. daadwerklike, doelgerigte en per persoon of geval gemotiveerde barmhartigheid;

4.3.3. die aanvraag van hulp en die gee daarvan deur een ressort by en aan ' $n$ ander ressort;

4.3.4. studie en spesialisering van persone en van bepaalde behoeftes deur die welsynsorganisasie wat op sy beurt as studieen spesialiserings- en skolingsbron vir diakens kan dien; 
4.3.5. inskakeling van susters by die bestuur en organisasie van die welsynsorganisasie op sinvolle wyse;

4.3.6. bevoegdheidstelling deur die inisieerders vir en van die welsynsorganisasie om gereformeerd Christelik te wees en om 'n scopus te hê wat die wye veld van nood en behoefte kan dek binne die beperktheid van die realiteite en prioriteite. Ek sou in elk geval die volgende sake binne die beperking wou sien as sake waarin altyd en direk op een of ander wyse diens gelewer kan word: armes, siekes, jeug, kinders, bejaardes; arm kerke; senuweelyers en dranksugtiges en drugverslaafdes en pasgetroudes; geskeie persone en hulle kinders. Die welsynsorganisasies kan geboue en klinieke en inrigtings oprig en onderhou en in stand hou en die diakonat kan die mense versorg met die barmhartigheid van Christus. Wat ek hier opgenoem het geld alles vir wit en swart en bruin mense en kerke. En voorts die uiters belangrike saak van die oprigting deur 'n klassis (vir die kerkverband) van 'n seminarie vir studie en opleiding van diakens/diakonesse (l.w. nie vir diakens en diakonesse nie want die Here roep tot die amp; maar as iemand in die amp staan dwing die ingewikkeldheid en gevarieerdheid van die nood tot studie en opleiding).

Sodoende, dink ek, sal die Here ons krag gee om die wa van die diakonaat uit die moddergat uit te stoot. Ons werk dan nie in 'n lugleegte nie en laat gawes nie onbenut nie. Die motivering kom uit die Bybel deur die Heilige Gees. En sodra ons weer gemotiveerd met kennis en insig te werk gaan en die diakens die hele gem ' nte in beweging kry al is dit net vir een persoon se leed of ook vir almal saam se ellende, sal ook onmiddellik die barmhartigheid van ons Hoëpriester uitskitter. Dit bring die wat help en gee en offer en die wat gehelp word en ontvang op die mees direkte manier in relasie met die Bron van alle barmhartigheid, ons hemelse Vader.

(Gelewer voor die GTV van die Witwatersrand, Mei 1977) 